\title{
SOME ASPECTS OF OPTIMAL UNEMPLOYMENT INSURANCE
}

\author{
Martin Neil BAILY* \\ Yale University, New Haven, CT (06520, U.S.A.
}

Received September 1977, revised version received August 1978

\begin{abstract}
*The original version of this paper was written for the Office of ASPER of the U.S. Department of Labor in 1975. This is a revision of 'Unemployment insurance as a social insurance program' presented at the ISPE Conference on Social Insurance held near Tokyo, Japan in May 1977. I would like to thank participants at this conference, M.A. Baily, G.S. Fields and the referees for helpful comments. My recent work on this topic has been funded by the National Science Foundation.
\end{abstract}

\section{Introduction}

The possibility of becoming unemployed represents an important source of income uncertainty for workers. All advanced economies and even many developing economies have responded to the existence of this uncertainty by providing a program of unemployment insurance (UI). In all cases I know of this program is provided by the public sector, although there are sometimes supplementary union-related private programs as well. At the time the US program was initiated there was some recognition that when a worker is unemployed there are both voluntary and involuntary aspects involved. There are several provisions that are designed to eliminate what were seen as possible abuses of the program. For example, recipients are required to register with the Employment Service and to actively seek work, ${ }^{1}$ while firms pay taxes into the program based upon an experience-rating.

The more recent development of search theory has brought out clearly that the intensity with which people search for jobs and the wage they are willing to accept are key determinants of the length of a spell of unemployment. This means, in turn, that the payment of UI benefits will change the behavior of individuals and the length of spells of unemployment. Martin Feldstein $(1973,1974)$ has been one of the most important critics of the UI program. He argued that it raises the rate of unemployment and, further, that many of those who receive benefits are not particularly low in the income distribution. Partly stimulated by Feldstein's criticisms, there has

\footnotetext{
${ }^{1}$ Workers awaiting recall to their previous employment do not have to search.
} 
been a great deal of research directed at measuring the extent of the adverse incentive effects and, specifically, estimating the magnitude of the increase in unemployment caused by the program. ${ }^{2}$

The empirical studies have studies have certainly been useful--indeed their results will be used later in this paper-but they do not go directly to the policy issue. They do not tell us whether or not the value of the existing UI program outweighs its costs. Nor do they give direct guidance as to the optimal benefit level and means of payment, if it turns out to be desirable to have a program.

The taxes paid to finance UI are the insurance premiums or the direct costs of the program. ${ }^{3}$ Ignoring administrative costs, however, all taxes are paid back as benefits. Thus, it is the change in private behavior induced by UI that is important, because it introduces a dead weight cost of the program. Directly on the tax side, this shows up because by prolonging the duration of a spell of unemployment, workers raise the tax needed to finance a given benefit level. Another side of this coin is the reduction in real output that accompanies an increase in unemployment. A worker who remains unemployed rather than accepting a job makes the choice on the basis of its impact on his or her private income not on the basis of its impact on social product. The benefit received while unemployed and the tax paid while employed open a gap between the private and social calculation.

This analysis considers certain aspects of the optimal insurance calculation. Workers are taken as all identical and subject to a probability of layoff. If laid off, they remain in the labor force and search for jobs, but the UI program causes them to become more choosy about jobs they are willing to accept and to search less intensely than is socially optimal. This is often called the moral hazard problem of the insurance. To set against this, there is an insurance gain of reduced income risk for workers. The optimal benefit level occurs when marginal costs and gains are balanced. The model is, therefore, an application of established ideas in the insurance literature to the labor market. ${ }^{4}$ The use of deductibles and coinsurance is well established in other insurance areas and they are, in fact, used in the current US UI program also. The gap between wage income when employed and benefit level when unemployed is a form of coinsurance. This model will consider in detail the optimal benefit level, i.e. the optimal coinsurance rate. Most States

\footnotetext{
${ }^{2}$ See for example Fields (1977) which also gives many references, Classen (1975), Ehrenburg and Oaxaca (1976), Marston (1975), Baily (1974b) and an earlier study of Chapin (1971).

${ }^{3} \mathrm{UI}$ taxes in 1976 were $\$ 7.9$ billion. This is roughly $1 \frac{1}{2} \%$ of the gross anmual wage receipts of production and nonsupervisory workers in the private sector. Data on the UI program are available from the report of the Staff on the Subcommittee on UI (1976).

${ }^{4}$ The analysis is of UI as a public finance problem in the spirit of earlier work on health insurance such as Arrow (1963), Pauly (1968) and Ehrlich and Becker (1972).
} 
do not pay a benefit for the first week of unemployment and this means there is in practice a 'deductible.' This model will find, however, that for UI a deductible is hard to justify. In fact, there is a case instead for shifting towards a 'redundancy payment' combined with somewhat lower weekly benefits.

The model used does not do full justice to the optimal insurance problem. Many interesting features of the problem are ignored. The focus is on incentive effects within a governmentally organized program and only on certain aspects of this issue. Some of the simplifications used will be discussed as the model is developed, but I should note one important question not touched on at all. Throughout this paper all workers are assumed to be alike. However, one reason why private insurance markets can fail to exist is the adverse selection problem. In reality not all workers are alike, they differ in their probabilities of being laid off. If private insurers were unable to estimate individual-specific layoff probabilities, then a private UI system could fail. ${ }^{5}$ A compulsory government program prevents adverse selection from driving out the insurance coverage, but of course it is still true that when workers are not all alike, some of them have much more to gain from the program than others, and I am ignoring this. ${ }^{6}$

\section{The basic model of optimal unemployment insurance}

The main assumptions of the model used are as follows:

(a) A two-period model will be used in which workers start out being employed in the first period and then face some probability of being laid off in the second. Allowing two periods rather than one permits the inclusion of private saving by workers as a method of self-protection against the possible decline in income. A more fundamental question is: why not consider the entire working life of the worker? Flemming (1978) has extended the framework used here to the case where workers consume out of lifetime income and his results can be compared with mine. The issue is not a trivial one because the longer the time-horizon the easier it is for workers to smooth their own consumption without help from an insurance program.

\footnotetext{
${ }^{5}$ See, for example, Wilson (1976) for a discussion of this issue. Since the existing government Ul program, as we shall see, provides as much insurance as most workers wish to pay for, we do not really know whether or not private UI could operate profitably. Another difficulty private insurance would face is the problem of diversifying the risks, since layoffs have a market cyclical pattern.

${ }^{6}$ For example, a young unemployed worker with general skills in a large diversified labor market is not in the same position as an older unemployed worker with a specific, obsolete skill in a small town in a depressed area. It should be emphasized, however, that UI cannot be designed to solve all labor market problems. Help in other forms can be given to structurally unemployed workers, especially in ways that help to overcome rather than perpetuate the underlying structural problem.
} 
Although certainly most families do make some attempt to prepare for retirement, a fairly short time-horizon for smoothing short-run income fluctuations does seem to be consistent with observed saving and consumption functions. ${ }^{7}$ The designers of the program certainly had in mind a time-horizon that was fairly short-perhaps even shorter than the two-period (taken as two-year) horizon I assume.

(b) Consumption is taken as the only argument of a worker's strictly concave three times differentiable utility function. This means $I$ will not be giving a lot of attention to the utility of leisure. This is largely because the unemployed are viewed here as active labor-force participants engaged in job-search not as inactive persons who are simply enjoying leisure. Even to the extent that job-search is not a full-time activity, there is, in addition, an offsetting disutility of unemployment in our work and success-oriented society. However, those who disagree with this need not reject the model. I will point out later how including the value of leisure would change the findings.

A more difficult issue concerns possible variations in hours worked if employed. Allowing for this would add a good deal of complexity to the model. It might be an interesting extension of the analysis to consider partial support from UI when there is short-time work.

(c) The interest rate and the pure rate of time-preference are both set equal to zero. This is a curious assumption in the light of the short time horizon, admittedly, since high values for these parameters are a possible reason why observed planning horizons look short. The assumption was made in order to simplify the algebra and focus on those parameters that looked most important for this problem. It is not hard to see how the results would be modified if nonzero values for these two rates were included.

(d) Workers face an exogenous, fixed probability of layoff in period two and then search for new jobs. These are strong conditions to impose although they are perfectly standard ones within the search literature. The division of risks between firms and workers and the impact of UI on the layoff decisions of firms is a question I have analyzed elsewhere [Baily (1974a, 1974b) and (1977)] as has Feldstein (1976). If there is an effective experience-rating provision in the program then as a first approximation one can ignore the firm's side of the decision. Not untelated to this question, however, is the fact that some workers who are laid off do not search for new jobs, but wait to be rehired by the firm that laid them off. For the present it is assumed that all unemployed workers do search for jobs, but some discussion of the implications of changing this assumplion, both for the theory and for the interpretation of the evidence are given in section 6 .

(e) Externalities in the search process are ignored. This means the duration

The work of Friedman (1957) talked of a three-year horizon. 
of a spell of unemployment of a worker is assumed to be independent of the search behavior of other workers. Like point (d) this is a complex question, awkward to incorporate properly into the model. There are two offsetting influences just as there are, for example, in the analysis of externalities in research and development. If two workers are both looking for the same job they may both search more intensely than is socially optimal. Some of the incentive to acquire information comes from the desire to keep ahead of the other person rather than to acquire information with a social value. ${ }^{8}$ On the other hand, one worker may be able to benefit from the search activity of another worker by observing his behavior or by questioning him about his search findings. This factor suggests less search activity will occur than is socially optimal. An extra ingredient that makes the problem awkward is that UI does not subsidize search, but income while searching, the two being far from identical.

It is not clear either of the two externalities is terribly important empirically and presumably their net impact is less so. It will also be argued below that when the simple theory is compared to observed behavior, the result will be valid even if there are externalities, since it will be the social cost that is inferred from the data.

The formal model is now developed. The probability of being laid-off in the second period is $(1-\alpha)$ so that $\alpha$ is the probability of being retained, taken throughout this analysis as a fixed parameter with $0 \leqq \alpha \leqq 1$. A worker who is laid off spends a fraction $(1-\beta)$ of the second period unemployed so that $\beta$ is the fraction of the period that a laid-off worker spends reemployed at $a$ new job. Clearly $0 \leqq \beta \leqq 1$. Throughout this and the next section $\beta$ is assumed to be non-stochastic. This is changed in sections 4 and 5. Let $y$ be wage income from the original employment held in period one and let $y_{n}$ be the income from a new job should the worker be laid off and find reemployment. The wage income $y_{n}$ that the worker is willing to accept is then a decision variable with an impact on the duration of unemployment. Let $c$ measure the intensity of search expressed in income units so that $c$ also measures the cost of search. Recalling that $\beta$ is the fraction of the period spent reemployed we will now assume:

$$
\beta=\beta\left(c, y_{n}\right), \quad \frac{\partial \beta}{\partial c}>0, \quad \frac{\partial \beta}{\partial y_{n}}<0 \quad \text { for } \beta \in(0,1) .
$$

If $t$ is the rate of UI tax levied on wage income then the total UI tax raised per worker is $\left(y t+\alpha y t+(1-\alpha) \beta y_{n} t\right)$. The first term is the tax from the first period and the second and third terms the tax from the second period, given

\footnotetext{
${ }^{8}$ Activities such as getting in line early or pushing others out of the way fall into this category.
} 
either retention or layoff plus reemployment. If the level of UI benefit (expressed like wage income as a flow per period) is $b$, then the average rate of benefits paid out is $(1-\alpha)(1-\beta) b$. It is assumed that all taxes, but no more, are paid out as benefits. This gives:

$$
y t+\alpha y t+(1-\alpha) \beta y_{n} t=(1-\alpha)(1-\beta) b
$$

as the UI budget constraint. ${ }^{9}$ If we then define $\mu$ as the ratio of benefits to the tax rate we have:

$$
b=\frac{\left[(1+\alpha) y+(1-\alpha) \beta y_{n}\right] t}{(1-\alpha)(1-\beta)} \equiv \mu t
$$

and hence: $\mu=\mu\left[\beta\left(c, y_{n}\right), y_{n}\right]$. This means that the ratio of benefits to the tax rate depends upon the decisions of workers. Define $y_{l}$ as a worker's income during the second period if he suffers a layoff with unemployment and then reemployment

$$
y_{i}=(1-\beta)(b-c)+\beta y_{n}(1-t) .
$$

If $s$ is the amount of savings made in the first period, a worker's two period expected utility is given by: 10

$$
V=U(y(1-t)-s)+\alpha U(y(1-t)+s)+(1-\alpha) U\left(y_{l}+s\right) .
$$

First of all the full social optimum is found by maximizing $V$ simultaneously with respect to $c, s, y_{n}$ and $(b, t)$. This will not give a trade-off between insurance and incentives, but does provide conditions giving the socially optimal search and acceptance behavior which can be used for comparison

${ }^{4}$ In a private insurance program there may be no positive values of $b$ and $t$ that satisfy (2) the adverse selection problem. In a compulsory governmental program, however, this we can reasonably assume that a solution to eq. (2) cxists.

\footnotetext{
${ }^{10} \mathrm{~A}$ worker's consumption, therefore, depends upon his income during the entire second period. This may involve some capital market manipulation with the period. A more important aspect of the formulation is that the value of finding a high-paying new job $\left(y_{n}\right)$ only lies in its increment to income in the second period. A more general analysis would include specifically a term measuring the 'bequest' value for future periods from $y_{n}$. For many workers, however, the specification used here is appropriate because they expect in future periods to be rehired in their original jobs (at $y$ ). 1 he value of $y_{n}$ is as a short-term job. Taking account of the longer term value of a high $y_{n}$ for workers making permanent job changes would make little or no difference to the derivation of the optimal UI benefit. It would change the form of the optimal acceptance conditions (eq. (6) and (7) below), although even there the interpretation and implications of the conditions would be very similar to that obtained here.
} 
with the principal model with a trade-off. Also there may be some empirical relevance to the fully optimal case. To save space, details of the maximization and the simplification of the results are not reproduced. They are contained in the ISPE conference version of the paper cited in the opening footnote, available from the author. The conditions giving socially optimal values of $c$ and $y_{n}$ (search intensity and acceptance level) are: ${ }^{11}$

$$
\begin{gathered}
\frac{\partial \beta}{\partial c}\left[y_{n}+c\right]=(1-\beta), \\
-\frac{\partial \beta}{\partial y_{n}}\left[y_{n}+c\right]=\beta .
\end{gathered}
$$

Eq. (6) says that the marginal return from more intensive search $(\partial \beta / \partial c)$ $\left(y_{n}+c\right)$ is equated to the marginal cost (an increment of one over the period $(1-\beta)$ of job search). (7) says that the marginal cost of postponing acceptance $\left(-\partial \beta / \partial y_{n}\right)\left(y_{n} \mid c\right)$ is equated to the marginal return of a higher paying now job (an increment of one over the period $\beta$ of employment at the new job). The reason this maximization produced this result is that in the evaluation of $\partial y_{l} / \partial c$ and $\partial y_{l} / \partial y_{n}$ the effect of variations in $c$ and $y_{n}$ on $\mu$ the ratio of benefits to taxes was included. This is as if workers were taking account of the effect of changes in their own behavior on the budget of the overall UI system. The optimal savings behavior is given from:

$$
U^{\prime}(y(1-t)-s)(-1)+\alpha U^{\prime}(y(1-t)+s)+(1-\alpha) U^{\prime}\left(y_{1}+s\right)=0 .
$$

And, given the efficient search behavior (6) and (7), the optimal tax (and benefit) level is determined by:

$$
\begin{aligned}
& y\left[U^{\prime}(y(l-t)-s)+\alpha U^{\prime}(y(1-t)+s)\right]+y_{n}\left[(1-\alpha) \beta U^{\prime}\left(y_{l}+s\right)\right] \\
= & {\left[y(1+\alpha)+y_{n}(1-\alpha) \beta\right] U^{\prime}\left(y_{l}+s\right) . }
\end{aligned}
$$

Inspection of (8) and (9) shows that if full insurance is provided $(b=y(1-t))$ and consequently workers save nothing, then this will satisfy the optimal conditions along with (6) and (7). Provided $U^{\prime \prime}<0$ this will be a maximum solution. This solution equates the marginal utility of consumption in the first period with the marginal utility in the second, whether employed or unemployed.

\footnotetext{
${ }^{11}$ The derivatives are all taken after substituting $b=\mu t$ into the equations. The maxima are always found with respect to the level of operation of a balanced-budget program (balanced over the two periods not within the 'downturn' period 2 alone).
} 
Since search behavior is set to be efficient, in retrospect it is not surprising to find this result, but in prospect it seemed that private saving might be a substitute for UI even in this case. The reason this does not happen is that buying insurance is more efficient under these assumptions than is saving. Saving implies a cut in current consumption and an increase in future consumption. This increases total utility only if some adverse event actually occurs. Buying insurance is a sort of contingent saving. The payoff comes only if the adverse event occurs. Private saving is, of course, efficient to smooth out known nonstochastic income fluctuations. The dominance of insurance over saving does depend upon the absence of incentives. It is important to understand the limitations of saving in the context of uncertainty to see why it does not dominate insurance later on.

The fully efficient solution can also provide some insight into a puzzle. If it is really true that UI benefits cause the adverse effect on job search that are claimed for them, and hence unemployment, why is it that, for example, Germany has been able to maintain such low unemployment rates even though they have a generous UI program? Workers receive between $60-80 \%$ of take-home pay. Just as in the U.S., workers receiving benefits must register with the employment service. But, unlike the U.S., this service is very efficient and is the source of new jobs for most workers and of new workers for most firms. To a considerable extent, therefore, the efficient amount of search is achieved by means of subsidizing search. Efficient job acceptance is achieved by means of the threat of removal of benefits from a reluctant worker reinforcing the extremely strong work ethic that exists in the German labor force. There are, of course, other factors involved in low German unemployment rates, specifically the manipulation of immigration flows to suit the business cycle. But the institutional arrangement of the employment service seems to prevent high UI benefits from becoming a problem. ${ }^{12}$

The main model of this section is now developed. It assumes that workers set their individual search and acceptance behavior taking the prevailing UI benefit and tax rates as given (i.e. workers now ignore the effect of their own behavior on the overall UI system). The optimal benefit and tax rates are then set, given the behavior of workers. The worker's expected utility is $V$ as in (5). The worker chooses $s$ and $c$ and $y_{n}$ taking $t$ and $b$ as given, which gives search intensity and acceptance conditions:

\footnotetext{
${ }^{12}$ The discussion in this paragraph is based upon an interview between the author and representatives of the German employment/unemployment insurance service, the Institute für Arbeitsmarkt und Berufsforschung in Nürnburg. Since writing this I have seen the work of Wolfgang Franz (1977) who finds a major impact of UI on German unemployment. This would lead one to the view that things are not as different in Germany as I assert, although there is some question as to the consistency of Franz's findings with the observed very low rate of unemployment in Germany in the 1960 s.
} 


$$
\begin{aligned}
& \frac{\partial \beta}{\partial c}\left[y_{n}(1-t)+c-b\right]=(1-\beta), \\
& -\frac{\partial \beta}{\beta y_{n}}\left[y_{n}(1-t)+c-b\right]=\beta(1-t) .
\end{aligned}
$$

Compare these conditions with the efficient ones (6) and (7). In (10) the private calculation of search and acceptance looks at the change in private income as a result of finding a new job, namely, $y_{n}(1-t)+c-b$ instead of $y_{n}$ $+c$. Since the former is much smaller than the latter, i.e. the private return from search and acceptance is lower than the social return because of UI benefits (and taxes), we would expect search intensity to be lower and the acceptance wage income higher. To examine this, totally differentiate (10) and (11), define $L_{c c}, L_{y y}$ and $L_{c y}$ as the second partials of $y_{l}$ and define $\beta_{c}$ $=\partial \beta / \partial c$ and $\beta_{y}=\partial \beta / \partial y_{n}$. These then give:

$$
\left[\begin{array}{cc}
\left(L_{\mathrm{cc}}-\beta_{c}^{2} A\right) & \left(L_{c y}-\beta_{c} \beta_{y} B\right) \\
\left(L_{y c}-\beta_{c} \beta_{y} A\right) & \left(L_{y y}-\beta_{y}^{2} B\right)
\end{array}\right]\left[\begin{array}{l}
\frac{\mathrm{d} c}{\mathrm{~d} t} \\
\frac{\mathrm{d} y_{n}}{\mathrm{~d} t}
\end{array}\right]=\left[\begin{array}{c}
\beta_{c} \frac{(1-\beta)}{t} A \\
\beta_{y} \frac{(1-\beta)}{t} B
\end{array}\right],
$$

where

$$
A=\frac{t}{1-\beta}\left(y_{n}+\mu\right), \quad B=\frac{b-c t}{(1-\beta)(1-t)} .
$$

Provided $b>c t$ both $A$ and $B$ are positive, and we also know that $L_{c c}<0, L_{y y}$ $<0$ and $L_{\mathrm{cc}} L_{y y}-L_{\mathrm{c} y}^{2}>0 .{ }^{13}$ Necessary and sufficient conditions for $\mathrm{d} c / \mathrm{d} t<0$, $\mathrm{d} y_{n} / \mathrm{d} t>0$ can be obtained from (12) but these conditions do not seem to be reducible into a very simple form. Sufficient conditions are given by:

$$
\begin{aligned}
& \left|B_{c} A L_{c c}\right| \geqq\left|\beta_{y} B L_{c y}\right|, \\
& \beta_{y} B L_{y y}|\geqslant| \beta_{c} A L_{c y} \mid,
\end{aligned}
$$

\footnotetext{
${ }^{13}$ These conditions are known because $y_{i}$ is maximized. The condition $b>c t$ requires an estimate of $c$ the search cost, but e.g. if $t=4 \%$ a common tax rate, it would require search cost more than 25 times the benefit level to violate the condition.
} 
but these are stronger than necessary. Futhermore, the later analysis requires only the weaker condition $\mathrm{d} \beta / \mathrm{d} t<0$. The necessary and sufficient condition for this is:

$$
\left[\beta_{c} \beta_{y}\right] Q^{-1}\left[\begin{array}{l}
\beta_{c} A \\
\beta_{y} B
\end{array}\right]<0
$$

where $Q$ is the $2 \times 2$ matrix in (12). This condition will be assumed to be satisfied, i.e. the duration of a spell of unemployment $(1-\beta)$ is increased by the payment of UI benefits.

The condition determining savings is of the same form as (8). The effect of UI on private savings depends (awkwardly) on the sign of $U^{\prime \prime \prime}$. A sufficient (but not necessary) condition for an increase in UI benefit level to reduce private savings is that $U^{\prime \prime} \geqq 0$. This condition is satisfied by the quadratic, constant relative risk aversion and constant absolute risk aversion utility functions. We can, therefore, say with some confidence that $\mathrm{d} s / \mathrm{d} t<0$. The UI program discourages private saving, as one would certainly expect. As $b$ increases so that $y_{l} \rightarrow y(1-t)$ we know from our earlier discussion that $s \rightarrow 0$.

The social policy question is now considered. Given that workers will change their search behavior as a result of UI, what are the conditions determining the optimal benefit level? The optimal policy sets $b$ and $t$, subject to the UI budget constraint, and the maximizing behavior of workers. This means that $V$ is a function of the form $V=V\left(c, y_{n}, s, \mu, t\right)$. But since the first three partials of this function are all zero from the maximizing behavior of workers (a simple envelope property) this gives:

$$
\frac{\mathrm{d} V}{\mathrm{~d} t}=\frac{\partial V \mathrm{~d} \mu}{\partial \mu \mathrm{d} t}+\frac{\partial V}{i t}=0
$$

To evaluate this condition in a helpful way requires a good deal of manipulation. The basic technique is to expand the representative worker's utility by a Taylor series around the consumption level if unemployed. The details are given in the conference paper mentioned earlier. Condition (15) can be expressed as:

$$
\Delta C\left[\frac{-U^{\prime \prime}(\theta)}{U^{\prime}\left(y_{1}+s\right)}\right]=\frac{\left[(1-\alpha) y_{n}+(1+\alpha) y\right]}{2 y(1-\beta)}(-t) \frac{\mathrm{d} \beta}{\mathrm{d} t}-\frac{(1-\alpha) \beta t}{2 y}-\frac{\mathrm{d} y_{n}}{\mathrm{~d} t} .
$$

Let $C_{t}=1 \cdot(1-t)-s$ be consumption while employed in period one and $C_{u}$ $=l_{i}+s$ be consumption in period two if laid-off. Then $\Delta C=C_{e}-C_{u}$, which is 
the drop in consumption caused by a lay-off. The value of $\theta$ lies between $C_{e}$ and $C_{u}$. This gives the formally correct condition from which to determine the optimal benefit level, but it is not very intuitive. There are some simplifications that do not do too much violence to this exact condition and provide an optimality of much greater simplicity and intuitive appeal.

The left hand side of (16) is the term that measures the cost to workers of the income risk from the probability of layoff that they face. If UI taxes and benefits are increased, this reduces the variability of workers' income and consumption. The higher tax level lowers income while employed and the higher benefit level raises income while unemployed. Thus an increase in taxes and benefits reduces the left hand side of (16). The first expression on the right hand side of (16) is a measure of the distortion of search behavior as a result of UI. The derivative $\mathrm{d} \beta / \mathrm{d} t$ is negative since unemployment duration rises with higher benefit and tax levels (in fact $\beta$ is a function of search intensity (c) and acceptance wage level $\left(y_{n}\right)$, so the derivative $\mathrm{d} \beta / \mathrm{d} t$ is a function of $\mathrm{d} c / \mathrm{d} t$ and $\left.\mathrm{d}_{y_{n}} / \mathrm{d} t\right)$. These two terms, therefore, give the important elements in the calculation of the optimal benefit level. The last term in (16) derives as follows. If UI benefit and tax levels are increased workers become choosier about jobs they will accept ( $y_{n}$ increases). Since the tax paid is specified as a payroll tax, however, the higher is $y_{n}$, the larger is the worker's UI tax burden. This then reduces slightly the distortion of private search behavior. Since in practice the UI program in the US is financed by a proportional tax only on a wage base, the effect of this last term can safely be ignored. Even ignoring this institutional feature the term would be very small relative to the two other terms in (16). ${ }^{14}$

Provided $y$ and $y_{n}$ are not too far apart, $\left[(1-\alpha) y_{n}+(1+\alpha) y\right] / 2 y=1$. This will be assumed to be true.

$\beta$ is the period of reemployment and $(1-\beta)$ is the period of unemployment. Since $b=\mu t$ we can say as approximation that:

$$
\frac{-t}{(1-\beta)} \frac{\mathrm{d} \beta}{\mathrm{d} t} \simeq \frac{b}{(1-\beta)} \frac{\mathrm{d}(1-\beta)}{\mathrm{d} b},
$$

recognizing that since $\mu$ increases with $b$ the right hand side is a little less than the left.

Look now at the left hand side of (16) and the definitions of $C_{e}$ and $C_{u}$ given below the equation. Then as an approximation:

$$
\Delta C\left[\frac{-U^{\prime \prime}(\theta)}{U^{\prime}\left(y_{l}+s\right)}\right] \simeq \frac{\Delta C}{C_{e}}\left[\frac{-C_{u} U^{\prime \prime}\left(C_{u}\right)}{U^{\prime}\left(C_{u}\right)}\right] .
$$

\footnotetext{
${ }^{14}$ Ignoring this term does not mean the cost of an increase in the tax rate is ignored. This cost enters the left hand side of (16). Income while employed is reduced by higher UI taxes. Nor is

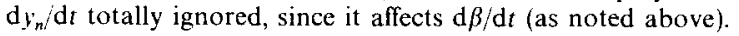


Where again the right hand side is a little less than the left. The expressions (17) and (18), therefore, contain minor and offsetting biases which allow us to express the optimal benefit condition as:

$$
\frac{\Delta C}{C_{e}}\left[R\left(C_{u}\right)\right]=E_{b}^{u} .
$$

Eq. (16) said that the level of the UI benefit and tax are set so that the marginal reduction in the welfare cost of income uncertainty just equals the marginal increase in the welfare cost of the distortion of the private job search decision. Eq. (19) gives the approximation of this expression, which expressed verbally is as follows.

Approximate criterion for optimal benefit level from the basic model: The optimal unemployment insurance benefit level is set when the proportional drop in consumption resulting from unemployment, times the degree of relative risk aversion of workers (evaluated at the level of consumption when unemployed) is equal to the elasticity of the duration of unemployment with respect to balanced budget increases in UI benefits and taxes.

\section{Applying the optimality condition}

Some assumptions that correspond roughly with current worker behavior are now applied, to see if these can tell us about the appropriate size of benefits to accompany such behavior and the insurance effectiveness of the present program. In the model of the previous section there were two ways that workers were assumed to operate in the capital market. First they can save from the first period. Second they are assumed by the specification of the model to be able to set their consumption level in the second period according to their total income available in the second period (plus savings of course). The interpretation of this is that they can borrow or get credit within the period. This seems a reasonable empirical assumplion. Rent or mortgage payments can be postponed as can utility bills and charge card payments. While it is certainly not true that workers prone to unemployment have the same access to credit as the affluent middle class, they certainly have some access to credit.

It has been documented by amny household surveys, ${ }^{15}$ and is shown in an appendix, available on request from the author, for the National Longitudinal survey of mature males, that families prone to unemployment have rather small liquid assets saved to help smooth short-run income fluctuations. It will be assumed that one week's take-home pay is the amount saved. Reflecting the assumption of a fairly substantial ability to smooth

\footnotetext{
${ }^{15}$ See Baily (1974a) for a discussion and references.
} 
within period fluctuations, annual income is taken as the determinant of the level of consumption. Consider a worker who experiences an eighteen week spell of unemployment during one year. He, therefore, receives as income 34 wecks of wages, 17 weeks of UI benefits and also consumes saving equal to 1 week's wages. He receives only 17 weeks of benefits in line with the standard practice of commencing payment of UI only after a one week delay. If he was fully employed the previous year he received 52 weeks of wages and consumed 51 of them. The relation between $\triangle C / C_{e}$, the drop in consumption, and $b / y$ the ratio of weekly UI benefit to weekly after-tax wage income is then: ${ }^{16}$

$$
\begin{aligned}
& \frac{\Delta C}{C_{e}}=\frac{51-34-17 b / y-1}{51}, \\
& \frac{b}{y}=\left[0.314-\frac{\Delta C}{C_{e}}\right] 3.00 .
\end{aligned}
$$

This relation is used to compute $b / y$ for various values of $\Delta C / C_{e}$ as set out in table 1 .

Table 1

Values of the percent of take-home pay to be covered by UI implied by different values of the proportional drop in consumption from a spell of unemployment.

\begin{tabular}{llll}
\hline$\Delta C / C_{E}$ percent & $\begin{array}{l}\text { Percent of } \\
\text { pay covered }\end{array}$ & $\Delta C / C_{E}$ percent & $\begin{array}{l}\text { Percent of } \\
\text { pay covered }\end{array}$ \\
\hline Greater than 31.4 & 0 & 15 & 49.2 \\
30 & 4.2 & 10 & 64.2 \\
25 & 19.2 & 5 & 79.2 \\
20 & 34.2 & 2.5 & 86.7 \\
\hline
\end{tabular}

The above calculation is intended to strike a middle ground. It could be objected that workers are not able to or should not be expected to smooth their consumption within as long a period as a year. Also, if the worker experiences his unemployment in several spells he will miss a week's benefits at the beginning of each spell. On the other hand if the worker is part of a family where other family members are working the reduction in family consumption will be smaller. Of course when a spouse works, the addition to real income is not the gross return from the marketplace but the increment above the value of work performed in the home. The unemployed worker could stop looking for a job and work at home, but this does not seem a very viable solution. In addition, it may be true that both husband and wife

${ }^{16}$ Actually $b / 52$ and $y / 52$ are the weekly values but the ratio, of course, is $b / y$. 
experience a spell of unemployment. Two workers means two chances of being unemployed. Elementary statistics says that the variance of income is likely to be reduced, but given the cyclical nature of unemployment probabilities there will be a positive correlation between the periods of unemployment of any two workers. It is not necessary to agree with the assumptions made here or the ones made below. Those who disagree can construct their own version of (20).

Several recent studies have attempted to measure the impact of UI on the duration of spells of unemployment. ${ }^{17}$ If an average spell of insured unemployment lasts 120 days and if an increase in the benefit-wage ratio from $45 \%$ to $55 \%$ raises duration by 3.6 days then the elasticity $E_{b}^{u}$ is equal to 0.15 . If the same benefit increase raises the duration by 7.2 days the elasticity is 0.3 and if by 9.6 days the elasticity is 0.4 . The empirical estimates mostly fall into this range, with the more recent estimates towards the high end. Table 2 presents alternative combinations of values of the UI benefit level, the elasticity of duration and degree of relative risk aversion that would be optimal. For example if we think the true elasticity of duration is low $(0.15)$ and that a degree of relative risk aversion of unity is plausible, then $\mathrm{UI}$ benefits should cover about $50 \%(49.2 \%$ in the table) of take-home pay. If, on the other hand, we think a high elasticity of duration is correct, then only if workers are very risk averse ( $R$ greater than unity) will anything more than a trivial level of UI benefits be optimal-given the assumptions of this model so fár.

Table 2

Values of the optimal percentage of take-home pay covered by UI for different values of duration elasticity and the degree of relative risk aversion (Eq. (19) is used).

\begin{tabular}{lccc}
\hline $\begin{array}{l}\text { Duration elasticity } \\
E_{b}^{u}\end{array}$ & \multicolumn{3}{c}{$\begin{array}{l}\text { Percent of take-home pay }(b / y) \\
\text { given degree of risk aversion }\end{array}$} \\
\hline 0.1 & $R\left(C_{n}\right)=0.5$ & 1.0 & 2.0 \\
0.15 & 34.2 & 64.2 & 79.2 \\
0.2 & 4.2 & 49.2 & 71.7 \\
0.3 & 0 & 34.2 & 64.2 \\
0.4 & 0 & 4.2 & 49.2 \\
\hline
\end{tabular}

It is hard to say exactly what degre of relative risk aversion is appropriate. It was suggested above that unity is a plausible value. The logarithmic utility function which has been widely used in other applications has a constant degree of relative risk aversion of unity. A worker with this utility function consuming $\$ 8,000$ over a year would be willing to pay an insurance premium of $\$ 177$ to avoid a one in ten chance of having to consume only $\$ 6,400$, a

\footnotetext{
${ }^{17}$ See the references cited in footnote 2
} 
$20 \%$ fall. The actuarily fair premium is $\$ 160$. The same worker would pay $\$ 85$ to avoid a one in ten chance of consuming $\$ 7,200$, a $10 \%$ fall. The fair premium is $\$ 80$. It is even hard to say exactly what the current benefit-wage ratio for the UI program is. The difficulty arises hecause different writers handle taxation, fringe benefits and other items differently. A common view is that about $50 \%$ of take-home pay is covered by UI, but Martin Feldstein has suggested $60-80 \%$ is more accurate. ${ }^{18}$

Provided we keep firmly in mind that the result depends crucially on the assumptions made in the model, it is worth summarizing the implications of this section.

Summary of the application of the basic model: With the stated assumptions of the model, with an assumed degree of relative risk aversion by workers of unity, and if workers do not prolong their duration of unemployment by very much as a result of UI payments (i.e. if $E_{b}^{u} \simeq 0.15$ ) then if the current benefit-wage ratio is $50 \%$ it is about right. If, howerer, the finding that workers do prolong their unemployment duration substantially as a result of $U I$ is correct (i.e. if $E_{b}^{u} \geqq 0.2$ ) then current $U I$ benefit levels look too high.

It is worth noting that if there are extermalities in the search process, the criterion for optimal UI is not necessarily being incorrectly applied. For example, suppose all jobs are alike and are quickly known about to most workers. Private search effort consists primarily of elbowing aside other workers; it has little social value. In this case, changes in the UI benefit level might induce large changes in the intensity of effort by competing workers, but would have little impact on the observed duration of unemployment. The measured $E_{b}^{u}$ would be very low, consistent with a high insurance benefit level-the socially correct solution.

Let me consider now how the model developed in section 2 and its application in this section would be changed by explicit consideration of the utility of leisure. A utility function with both consumption and leisure as arguments would certainly give a more general and complete model. Leisure

\footnotetext{
${ }^{18}$ In 1975 the average weekly benefit amount paid out by state UI services was about $\$ 70$, according to the Staff of the Subcommittee on UI 1976. The Bureau of Labor Statistics reported spendable average weekly earnings of production and nonsupervisory workers with three dependents taking standard tax deductions of $\$ 146$ in 1975 . This gives a ratio of $48 \%$. Feldstein points out that a large fraction of workers have working spouses which increases the attractiveness of the non-taxable UI benefit by raising the marginal tax rate. Fringe benefits, however, often amount to $10 \%$ or more of gross wages so that this would lower the calculated ratio. Feldstein downplays the relevance of fringe benefits, pointing out that a major item is pension contributions and the final pension received is often not very sensitive to the marginal weekly contribution. Feldstein usually uses a benefit level calculated from entitlement not actual pay-out. If people are not perfectly adept at using the system, they may receive less than their full entitlement. The $\$ 70$ figure comes from the accounts of the State programs. A referee of this paper suggested that computing the $48 \%$ replacement ratio from average weekly earnings is inappropriate. He felt that a figure lower than the average giving a higher caiculated replacement ratio was better. I do not agree. High-wage workers draw benefits about as much as low-wage workers according to Feldstein (1974). One can see from all this, if nothing else, that settling the issue is difficult.
} 
while employed would, of course, be total hours less hours on the job. Leisure while unemployed would be total hours less hours spent searching and search intensity could then be measured by the number of such hours. Searching for a job may be considered more or less unpleasant than working, depending upon one's individual taste. I would personally much rather work than look for work.

Rather than using the more general (but less easily tractable) framework, this paper specified a cost of search $c$ in income units. Within the model of this paper, therefore, the advantage to the worker of not having to spend time working during periods of unemployment could be allowed for as an offset to $c$, that is by adding the income equivalent of this advantage to $b-c$ in eq. (4). For this simple case the working through of the model would remain very much the same.

When parameters are tried in the model to see what can be said about the current UI program, then, of course, anyone giving a heavy weight to leisure would reduce the estimated optimal benefit level ceteris paribus. Note, however, that in the calculations used in this section no explicit estimate of search cost $(c)$ was made. Implicitly, I have assumed in this section that the cost of search and the psychic costs of being unemployed for an unemployed worker add up to about the same as the disutility of working when employed.

\section{Uncertainty in the duration of unemployment}

The specification of the models used in section 2 used a duration of unemployment $(1-\beta)$ that depended upon the search parameters of the worker, but was deterministic. The uncertainty involved in a worker's income was whether or not he would be laid off. A much better assumption is that the length of the spell of unemployment is also uncertain. It would be desirable to specify that $(1-\beta)$ is a random variable with a distribution that depends in some general way upon the search parameters $c$ and $y_{n}$. This would make it hardeer to handle the resulting model and so a somewhat simpler approach is adopted. Consideer the equation:

$$
(1-\hat{\beta})=\left[1-\beta\left(c, y_{n}\right)\right]+t
$$

Where the duration of unemployment $(1-\not{\beta})$ is a random variable consisting of a deterministic part $(1-\beta)$ that depends on the actions of the worker and $v$ a stochastic term with mean zero. ${ }^{19}$ Since we have that:

\footnotetext{
${ }^{19} \mathrm{This}$ is only an approximation. Strictly speaking, since $\beta+v$ is constrained to lie in the 0,1 interval, the distribution of $v$ cannot be completely independent of $\beta$.
} 
and

$$
E(1-\bar{\beta})=(1-\beta)
$$

$$
\operatorname{var}(1-\bar{\beta})=E\left(v^{2}\right)
$$

That part $(1-\beta)$ corresponds to our previous $(1-\beta)$ and is the average duration of unemployment. The variance of $v$ is the variance of duration.

This change will affect the worker's decision because of the increased uncertainty of income, for a given $b$. It will also affect the optimal benefit level. Consider first the search decision. Since the effect of search expenditure $c$ has now become uncertain while the cost remains certain, i.e. searching itself has become a gamble, we would expect a reduction in search intensity by risk-averse workers. Since turning down a job offer now involves taking a risk we would expect risk-averse workers to become less choosy about jobs and to lower $y_{n}$. The optimal conditions derived in section 2 implied:

$$
\frac{\partial y_{l}}{\partial c}=0, \quad \frac{\partial y_{l}}{\partial y_{n}}=0
$$

i.e. that a worker chooses his search intensity and acceptance wage to maximize his income during the period he is laid off [eqs. (10) and (11) are based upon this condition]. With the new specification we have:

$$
E_{v}\left[U^{\prime}\left(\tilde{y}_{l}+s\right) \frac{\partial \tilde{y}_{l}}{\partial c}\right]=0, \quad E_{v}\left[U^{\prime}\left(\tilde{y}_{l}+s\right) \frac{\partial \tilde{y}_{l}}{\partial y_{n}}\right]=0,
$$

Where $\tilde{y}_{l}=(1-\tilde{\beta})(b-c)+\tilde{\beta} y_{n}(1-t)$ is a random variable equal to the income of a laid-off worker, and $E_{v}$ is the expected value over the distribution of $v$. We then have that:

$$
\tilde{y}_{l}=(1-\beta)(b-c)+\beta y_{n}(1-t)-v\left[y_{n}(1-t)+c-b\right]=y_{l}-v \Delta Y,
$$

where $y_{l}$ is defined as in section 2 and is the expected value of the income of a laid-off worker and $\Delta Y$ is the change in income a worker experiences when he changes from unemployment to reemployment at a new job. Eq. (25) gives:

$$
\frac{\partial \tilde{y}_{l}}{\partial c}=\frac{\partial y_{l}}{\partial c}-v
$$


The analogous expression for $y_{n}$ is:

$$
\frac{\partial y_{1}}{\partial y_{n}}=\frac{\partial y_{1}}{\partial y_{n}}-\imath(1-t) .
$$

Making further use of Taylor expansions we can show that:

$$
\frac{\hat{c} y_{l}}{\hat{c}}>0 \text { and } \frac{\hat{c} y_{l}}{\partial y_{n}}>0 \text {. }
$$

Then since we know that $c^{2} y_{/} / \partial c^{2}, \lambda^{2} y_{/} / \imath y_{n}^{2}<0$ this confirms that search intensity will be lower and job acceptance lower at least for small variance of $r$, provided the solution changes continuously as the variance of $v$ goes from zero to some small positive value. This result means that we cannot say a priori whether the average duration of unemployment is increased or decreased by the addition of $v$. It is to be expected that savings will be increased as a result of the increase in uncertainty. As a result of the addition of $v$ the expected value of $\tilde{y}_{i}$ is below the maximized $y_{l}$ of section 2 . This can be shown from the fact that (23) has been replaced by (24). In addition, provided as before $U^{\prime \prime \prime} \geqq 0$, the expected marginal utility is larger than the marginal utility of the expected value. For both reasons, savings will be increased by $v^{20}$

Consider now the optimality criterion and how it is affected by uncertainty of unemployment duration. The expected utility $V$ is given by:

$$
V=U(y(1-t)-s)+x L(1(1-t)+s)+(1-\alpha) E_{1}\left[U\left(\bar{y}_{l}+s\right)\right] .
$$

As before we can assume the partial derivatives of $V$ holding $\mu$ and $t$ constant are zero and the optimality condition is the same as equation (15). The optimality criterion derived from (29) and (15) contains the same terms as the condition (16) of section 2, plus an additional term added to the left hand side of (16). This is given by:

$$
E_{v}\left[\frac{-U^{\prime \prime}(\delta)}{U^{\prime}\left(y_{l}+s\right)} v \Delta Y\left(1-E_{b}^{a}\right)\left(1+\frac{1}{1-\beta}\right)\right] .
$$

To simplify this, terms in $U^{\prime \prime}$ and higher will be ignored. This is a common, although not terribly satisfactory assumption, as is well-known. If we keep in

\footnotetext{
"Details are given in the mimeo paper al ailable from the authot
} 
line with earlier practice and approximate in a way that slightly reduces the expression we obtain for (30) the term:

$$
R\left(C_{u}\right) \rho^{2} \frac{\Delta Y}{C_{e}}(1-\beta)\left(1-E_{b}^{u}\right) \equiv R\left(C_{u}\right) \frac{F}{C_{e}},
$$

where $\rho=\sqrt{[\operatorname{var}(v)] /(1-\beta)}$ is the coefficient variation of the duration of unemployment, $\triangle Y(1-\beta)$ is the expected loss of income resulting from the spell of unemployment, and $F$ is defined from (31). Putting this into our previous criterion we have:

$$
\left[\frac{\Delta C+F}{C_{e}}\right] R\left(C_{u}\right)=E_{b}^{u}
$$

so that $\Delta C$, defined as the drop in consumption associated with a spell of unemployment of average duration, is now augmented by $F$, a positive correction factor. This criterion can, therefore, be described by the following.

Approximate criterion for optimal benefit level with stochastic unemployment duration: If there is uncertainty in the duration of unemployment, it is appropriate to add to the calculated drop in consumption used in computing the benefit level from the basic model a positive correction factor. The amount of this correction is higher, the greater is the uncertainty (the coefficient of variation) of the duration of unemployment, the greater is the income drop due to unemployment and the smaller is the elasticity of duration of unemployment with respect to $U I$ benefits.

One of the reasons that the earlier optimality criterion was applied independently of this section is that I have no very reliable estimate of the variance or coefficient of variation of the duration of unemployment. ${ }^{21}$ I simply chose a duration figure somewhat longer than the average for all workers in making the calculation. This has an appeal independently of any figures derived here. To provide an order of magnitude, however, assume that duration is distributed log normally with a mean of fifteen weeks and a coefficient of variation of 0.5 . This gives a smaller calculated drop in consumption:

$$
\frac{\Delta C}{C_{e}}=\frac{51-37-14 b / y-1}{51} .
$$

\footnotetext{
${ }^{21}$ This deficiency is being remedied. S. Nickell has some unpublished work on the distribution of completed unemployment spells for the U.K. that I have not seen. D. Coppock, a Yale graduate student, is estimating a distribution function for the probability of leaving unemployment.
} 
But the correction factor is now added to this:

$$
\frac{F}{C_{e}} \equiv \frac{\Delta Y(1-\beta) \rho^{2}\left(1-E_{b}^{u}\right)}{C_{e}}=\frac{0.25 \times(1-b / y) \times 15 \times\left(1-E_{b}^{u}\right)}{51}
$$

Then, for example, if the benefit-wage ratio is $50 \%$, (33) gives the proportional drop in consumption as 0.118 . But if $E_{b}^{u}$ is the low value of 0.15 the correction factor to be added to this is 0.031 . This means that with a degree of risk aversion of unity the left hand side of (32) equals 0.149 . This is almost equal to 0.15 . Hence with these numbers the first part of the summary of the application of the basic model remains true. Since a higher value of $E_{b}^{u}$ will lower the correction factor and raise the right hand side of (32), it is then certainly also true that the second part of the summary statement remains correct.

\section{A UI program that includes a redundancy payment}

Giving workers a fixed amount for each week they remain unemployed is not the only way of setting up a UI program. Although more general formulations are obviously possible, a simple form, where the total benefit received over the period is a linear function of the duration of unemployment, will be considered now:

$$
B=r+(1-\tilde{\beta}) b
$$

where $B$ is the total benefit received, $b$ is the flow payment as before, and we now have $r$ a redundancy payment as well. This is a fixed payment received by a worker who is laid off, an amount that does not depend upon when a new job is found.

Given the specification (35), a worker's income in the second period if laid off $\tilde{y}_{l}$ is now:

$$
\tilde{y}_{l}=r+(1-\tilde{\beta})(b-c)+\tilde{\beta} y_{n}(1-t)
$$

Without loss of generality we can think of $t=t_{0}+t_{1}$ as divided into $t_{0}$ which finances $r$ and $t_{1}$ which finances $b$. We then have:

$$
r=\left[\frac{(1+\alpha) y+(1-\alpha) \beta y_{n}}{(1-\alpha)}\right] t_{0}=\lambda t_{0}
$$

and $b=\mu t_{1}$, where $\mu$ is defined as before. These conditions ensure there is an expected balanced budget for the UI program. The maximum with respect to 
changes in $r$ and $t_{0}$ and $b$ and $t_{1}$ can then be found. A worker's search and acceptance conditions with both $r$ and $b$ have exactly the same form as before, although of course the solution values of $c$ and $y_{n}$ are changed by introducing the redundancy payment $r$. The optimal conditions derived earlier were from conditions for an interior maximum. The analogous (approximate) conditions for this problem are:

$$
\begin{aligned}
& {\left[\frac{\Delta C+F}{C_{e}}\right] R\left(C_{u}\right)=E_{b}^{u},} \\
& {\left[\frac{\Delta C \mid G}{C_{e}}\right] R\left(C_{u}\right)=H_{u} E_{r}^{u},}
\end{aligned}
$$

where

$$
\begin{aligned}
H_{u} & =\frac{(1-\alpha)(1-\beta)}{2} \\
& =\frac{\text { no. of workers laid-off } \times \text { weeks unemployed }}{\text { no. of workers in labor force } \times 52} \\
& =\text { average rate of unemployment due to lay-offs. }{ }^{22} \\
G & =H_{u} \rho^{2} \Delta Y(1-\beta), \quad F \text { defined by }(31) .
\end{aligned}
$$

If it is optimal to pay a positive redundancy payment and a positive weekly benefit then (38) (which has the same form as (32)) and (39) should be satisfied. $E_{r}^{u}$ is the elasticity of the duration of unemployment with respect to the redundancy payment $r$. In comparison with $E_{b}^{u}$, this elasticity is likely to be small. Paying $r$ has an income effect so that unemployed workers are less pressed financially to accept whatever jobs are available, but there is no substitution effect because prolonging the spell of unemployment does not result in more benefits received. The fact that prolonging a spell of unemployment does not lead to more benefits received means that as well as making $E_{r}^{u}$ smaller than $E_{b}^{u}$, there is also less social distortion cost from a given change in behavior. This is because these workers who are employed do not have to pay extra taxes to finance extra benefits for the unemployed. This is reflected in the presence of $H_{u}<1$ on the right hand side of (39). On both of these grounds the redundancy payment has a distinct advantage over the weekly benefit.

\footnotetext{
${ }^{22}$ The probability of a lay-ofs is $(1-\alpha)$ over two periods. $(1-\alpha) / 2$ is therefore, the ratio of the number of workers laid off to the size of the labor force. The duration of unemployment in weeks is $(1-\beta) 52$.
} 
The advantage of the weekly benefit lies in its superiority as insurance when the duration of a spell of unemployment is uncertain. Payment of a fixed sum to laid off workers. will overinsure those lucky enough to get jobs quickly and underinsure those who are unlucky in their search (i.e. differences in drawings of $v$ ). The algebra reflects this advantage of the weekly benefit $b$ in the fact that $F$ will be substantially greater than $G$ on the left hand side of (38) and (39) because $H_{u}<\left(1-E_{b}^{u}\right)$ for all reasonable parameter estimates. $^{23}$ The advantage to the weekly benefit disappears (as it should) if there is no uncertainty of unemployment duration $(\rho=0)$.

Although the lack of estimates for $\rho$ and $E_{r}^{u}$ precludes any very precise statement of the optimal policy mix, the following summarizes the findings:

Summary findings when model is generalized to include a redundancy payment: The relative sizes of the optimal weekly UI benefit and redundancy payment depend upon the uncertainty in the duration of a spell of unemployment and the importance of the incentive effects on workers behatior. The more important is the former the larger will be the weekly benefit. The more important is the latter the larger will be the redundancy payment.

The issue of negative or boundary values of the parameters is more relevant in this model than in the previous sections. If the incentive effects really are important then it might turn out to be optimal to set a zero weekly benefit or even, if it is admitted, a large redundancy payment combined with a tax on workers who do not find jobs quickly. Even though I have no hard evidence on this question, I have a prior expectation that such a solution the tax solution anyway-would be undesirable. This presumably implies a belief that uncertainty of unemployment duration is important. However some experimentation with possible parameter values in (38) and (39) suggests that a move to a smaller weekly benefit combined with a positive redundancy payment would be a welfare-increasing change. It is certainly hard to find plausible parameter values that would justify the combination of a fairly high weekly benefit and a negative redundancy payment (the first week of unemployment is not compensated) that characterizes the current U.S. program.

\section{Workers who do not search}

We know that a large fraction of layoffs are temporary layoffs where the workers eventually return to the firm that laid them off. ${ }^{24}$ Many such workers do look for short-term jobs while waiting to be recalled, ${ }^{25}$ but some others do no searching at all. In the formal analysis of the preceding sections

\footnotetext{
${ }^{23}$ A very large value of $H_{u}$ is 0.1 . A very small value of $1-E_{b}^{u}$ is 0.5 .

${ }^{24}$ See Feldstein (1975).

${ }^{2}$ See Bradshaw and Scholl (1976) and the discussion of the paper.
} 
it was implicitly assumed that all workers do look for new jobs. If this is not so, the first-order condition (10) becomes an inequality and the condition (11) is no longer relevant.

This issue is important for the interpretation of the empirical findings. The value of $E_{b}^{u}$ used in section 3 was estimated from data that included some workers who did not search at all and hence whose behavior was unchanged by small variations over time or, equivalently, compared cross-sectionally workers, some of whom did not search. Thus the elasticity figure used underestimated the responsiveness of the set of workers most relevant for the model.

Suppose the model were reworked to deal with this problem, how would it come out? The easy case is where there is no search whatever the level of UI benefits. In this case, there is no induced change in search so that full insurance can be given to all such workers. ${ }^{26}$ The much harder case is the one where workers are induced to stop searching by the presence of UI. It would not be possible to derive a general optimum condition in this case, because the welfare-maximum would have to be found by comparing the optimum with search to the situation with full-insurance and no search.

Having grappled with this extension of the analysis, there would remain the problem that because of the practical difficulty of distinguishing among workers it would be necessary to choose the optimal benefit level as a compromise between the findings for workers who do and for those who do not search. The results derived in this paper can be seen as one particular compromise. The nonsearching workers, with elasticities $E_{b}^{u}$ that are zero when measured at prevailing benefit wage ratios, are averaged in with the searching workers and this increases the optimal benefit level ceteris paribus derived from the models used here. Implicitly this says that the workers who do not search should be given full insurance. The particular compromise chosen, therefore, is the one most favorable to the UI program.

\section{Conclusion}

This paper has considered the welfare economics of unemployment insurance, taking the program as a social insurance provision for workers. Theoretical criteria for setting the optimal benefit level were derived and compared with the current program. A potential institutional change was examined which may have policy relevance. Although many important and interesting complications were ignored, it is hoped that the framework developed can lead on to more complete analyses.

\footnotetext{
${ }^{26}$ Provided we have removed the incentive to firms to make more lay-offs by experiencerating.
} 


\section{References}

Arrow, K.J., 1963, Uncertainty and the economics of medical care, American Economic Review 53, May, 141-73.

Baily, M.N., 1974a, Wages and employment under uncertain demand, Review of Fconomic Studies 41, January, 37-50.

Baily, M.N., 1974b, Unemployment and unemployment insurance, Department of Economics Discussion Paper, Yale University, December.

Baily, M.N., 1977, On the theory of layofs and unemploynent, Econometrica 45, July, 10431063.

Bradsahaw, T.F. and J.L. Scholl, 1976, The extent of job search during layoff, Brookings Papers on Economic Activity, no. 2, 515-26.

Chapin, G., 1971, Unemployment insurance, job search and the demand for leisure, Western Economic Journal 9, March, 102-106.

Classen, K., 1975, The effects of unemployment insurance evidence from Pennsylvania, Technical Analysis Paper No. 34, ASPER, U.S. Department of Labor.

Ehrenburg, R.G. and R.L. Oaxaca, 1976, Unemployment insurance, duration of unemployment and subsequent wage gain, American Economic Review, December, 756-66.

Ehrlich, I. and G.S. Becker, 1972, Market insurance, self-insurance, and self protection, Journal of Political Economy 80, July/August, 62348.

Feldstein. M.S., 1973, Lowering the permanent rate of unemployment, A study prepared for the use of the Joint Economic Committee of Congress (U.S. Government Printing Office, Washington).

Feldstein, M.S., 1974, Unemployment compensation: Adverse incentives and distributional anomalies, National Tax Journal 37, June, 231-44.

Feldstein, M.S., 1975, The importance of temporary layoffs: An empirical analysis, Brookings Papers on Economic Activity, no. 3, 72.5-45.

Feldstein, M.S., 1976, Temporary layoffs in the theory of unemployment, Journal of Political Economy 84, October, 936-58.

Fields, G.S., 1977, The direct labor market effects of the U.S. unemployment insurance system: A review of recent evidence, Industrial Relations, February.

Flemming, J.S., 1978, Aspects of optimal unemployment insurance: Search, leisure, savings and capital market imperfections, Journal of Public Economics, this issue, 403-425.

Franz, W., 1977, Unemployment insurance, international factor mobility and the labor market: The German case, paper presented to the ISPE Conference on Social Insurance, Japan, May, mimeo.

Friedman, M., 1957, A theory of the consumption function (Princeton University Press, Princeton).

Marston. S.T., 1975, The impact of unemployment insurance on aggregate unemployment, Brookings papers on economic activity, no. 1, 13 48.

Pauly, M.V., 1968, The economics of moral hazard: Comment, American Economic Review 58, June, $531-37$.

Staff of the Subcommittee on Unemployment Insurance, 1976, Statistics of the unemployment insurance program (U.S. Government Printing Office, Washington).

Wilson, C., 1976, A model of insurance markets with asymmetric information, Cowles Foundation Discussion Paper No. 432, mimeo, Yale University. 